
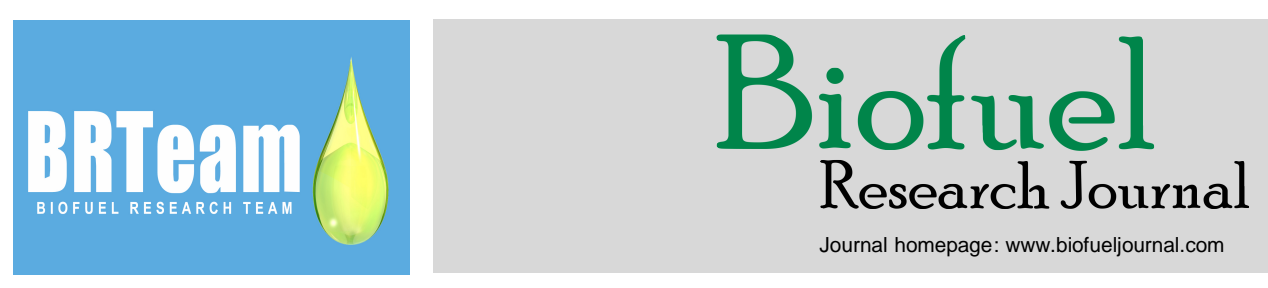

Original Research Paper

\title{
Stirred and non-stirred lignin solvolysis with formic acid in aqueous and ethanolic solvent systems at different levels of loading in a 5-L reactor
}

\author{
Solmaz Ghoreishi ${ }^{1, *}$, Tanja Barth ${ }^{1}$, Hailegebrel Derribsa ${ }^{2}$ \\ ${ }^{1}$ Department of Chemistry, University of Bergen, Norway, Allégaten 41, N-5007 Bergen, Norway. \\ ${ }^{2}$ Mjøsvegen 6J, 2380 Brumunddal, Norway.
}

\section{HIGHLIGHTS}

$>$ Oil yields increased and char yields decreased with a high loading in the reactor at stirred condition. $>$ In comparison with water-based system, ethanolbased system tended to give higher oil yields. $>$ Oil yields decreased, more or less, with increasing reaction temperature regardless of solvent type. $>$ The bio-oils from ethanol-based experiments had the highest $\mathrm{H} / \mathrm{C}$ and $\mathrm{O} / \mathrm{C}$ ratios.

$>$ The bio-oil composition produced in each solvent system was quite stable and independent of other reaction conditions.

\section{GRAPHICAL ABSTRACT}

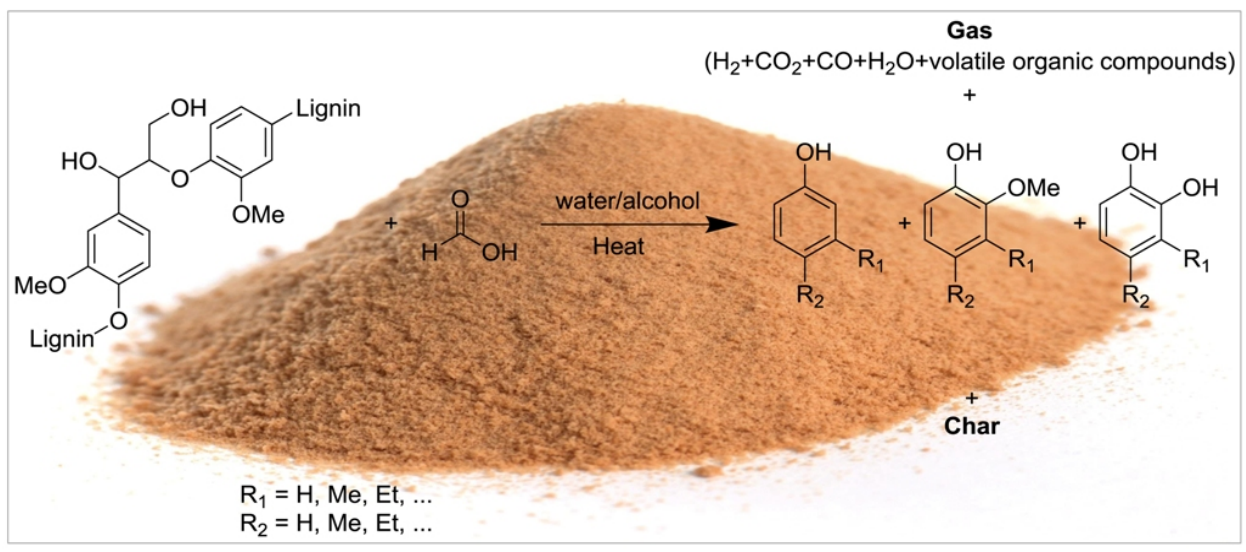

\section{ARTICLE INFO}

\section{Article history:}

Received 28 November 2018

Received in revised form 23 January 2019

Accepted 17 February 2019

Available online 1 March 2019

\section{Keywords:}

Lignin de-polymerization

Stabilization

Lignin-to-Liquid

5-L Scale

Stirring

\begin{abstract}
Lignin polymer is biologically and chemically stable and requires highly vigorous conditions for de-polymerization, and subsequent stabilization of the monomeric conversion products to prevent re-polymerization and char production. The Ligninto-Liquid (LtL) process is a solvolytic conversion of lignin with formic acid. Formic acid has been shown to both catalyze the de-polymerization and supply hydrogen that stabilizes the de-polymerization products. In this paper, lignin from Eucalyptus wood was used as the feedstock, and the LtL-process was performed in both aqueous and ethanolic solvent systems. The experimental variables were different levels of loading in the reactor, stirred and non-stirred conditions, and different reaction temperatures. The bio-oil consisted mostly of phenolic compounds, and the bio-oil yields differed with type of the solvent used, level of loading in the reactor, stirring condition, and operating temperature. More than $55 \mathrm{wt} \%$ of the lignin was recovered as bio-oil at $320{ }^{\circ} \mathrm{C}$ at stirred conditions when the reactor was loaded at high level. Overall, the ethanolic solvent together with maximum level of loading in the reactor under stirred condition resulted in the highest bio-oil yield. Elemental balance data for bio-oil and char yields and the molecular composition of the bio-oils were also investigated using, respectively, elemental analysis and GC-MS. Finally, principal component analysis was used as well to systematically explore the relationship between the bio-oil and char yields and the reaction conditions.
\end{abstract}

(c) 2019 BRTeam. All rights reserved.

* Corresponding author at: Tel.: +4790723929

E-mail address: Solmaz.Ghoreishi@uib.no

Please cite this article as: Ghoreishi S., Barth T., Derribsa H. Stirred and non-stirred lignin solvolysis with formic acid in aqueous and ethanolic solvent systems at different levels of loading in a 5-L reactor. Biofuel Research Journal 21 (2019) 937-946. DOI: 10.18331/BRJ2019.6.1.5 


\section{Introduction}

Environmental preservation is one of the major concerns in the $21^{\text {st }}$ century. Population growth, increasing living standards, increasing industrialization, and the motorization of the world have led to a steep rise in energy and fossil fuel consumption. Excessive consumption of fossil fuels to fulfill the energy demands has not only resulted in the depletion of the resources but also has largely contributed to greenhouse gas (GHG) emissions and global warming (Nigam and Singh, 2011; Tanaka et al., 2012). Thus, it is necessary to develop a bio-based economy, mainly based on renewable, sustainable, and economically viable energy sources. Since there is no single solution to the challenges faced, there will be a need for combined actions, including changes in behavior, changes in vehicle technology, expansion of public transport, and introduction of innovative fuels and technologies (Cherubini, 2010; Singh et al., 2010; Haghighi Mood et al., 2013; Kim et al., 2013). Utilization of biomass as a renewable and sustainable raw material for production of biofuels and other value-added chemicals through a biorefinery approach has recently received a great deal of attention as a promising alternative to fossil resources (Cherubini and Jungmeier, 2010; Bu et al., 2012; Kim et al., 2013). A biorefinery system comprises optimal and sustainable use of the renewable resources where the incoming raw material is completely converted into a range of products with high values (Kleinert and Barth, 2008; Gasson et al., 2010; Oregui-Bengoechea et al., 2015).

Emerging technologies for production of fuels from biomass have become an important subject because of their potential environmental impacts. Competition over biomass feedstocks as well as their different applications has been intensified because of increasing demands for biomass. Thus, to ensure sustainable use of biomass, one needs to identify the most promising routes for producing heat, power, fuels, and materials in terms of their technological, economic, and environmental performance (Gerber et al., 2011; GerssenGondelach et al., 2014). Biofuels, as an alternative to fossil fuels and a future leading supply of energy, are believed to increase supply security, reduce vehicle emissions, and provide farmers with a steady income (Nigam and Singh, 2011; Creutzig et al., 2015).

The greatest challenge faced in the biofuel arena is to produce renewable liquid fuels, which are suitable for use in motor vehicles. New fuels generated from renewable sources should preferably be compatible with the existing motor technology and infrastructure. This in fact facilitates direct substitution and mixing of conventional and renewable fuel types. Bioethanol produced from edible sources of carbohydrates and biodiesel produced from edible vegetable oils, are well-known examples of renewable and petroleum compatible first-generation biofuels. However, there are major challenges associated with large-scale production of these first-generation biofuels such as food $v s$. fuel conflicts, etc. Thus, much effort has been put into developing new processes for the production of second-generation biofuels from a variety of non-edible resources such as lignocellulosic biomass (Kleinert and Barth, 2008).

Lignocellulosic biomass is in fact considered as a suitable carbon raw material for the synthesis of functional carbon materials. It is cheap, abundant and does not negatively affect the human food supply chain (Zhang et al., 2011; Liu et al., 2015). Lignocellulosic biomass is a heterogeneous feedstock composed of three principal components of different nature: cellulose, hemicelluloses, and lignin. Various types of biofuels and value-added chemicals have been already produced from cellulose and hemicellulose, and the technical feasibility of the processes involved have been well demonstrated. The third major consistent, i.e., lignin, is a cross-linked amorphous copolymer, defined as a complex polyphenolic network of three basic phenylpropane monomers (p-coumaryl alcohol, coniferyl alcohol, and sinapyl alcohol). Lignin as a feedstock has a significant potential for the production of bio-based aromatic fuels and chemicals (Azadi et al., 2013; Løhre et al., 2016). Since, the high cost of cellulosic ethanol has limited its market, it will be essential to develop an efficient and appropriate thermochemical method for conversion of waste lignin streams into fuels and valuable bulk and specialty chemicals like aromatics, phenols, aromatic ethers, vanillin, etc. However, there are still major challenges faced for the valorization of lignin to these valuable commodities (Singh et al., 2014; Kristianto et al., 2017; Oregui-Bengoechea et al., 2017).

Various methods have been, and are being, explored to develop high-yield processes for the conversion of lignin-rich residual materials to fuels and bulk chemicals. One of such processes aimed at lignin valorization was reported by Kleinert and Barth (2008), comprising simultaneous de-polymerization of the lignin structures with subsequent hydro-deoxygenation of the lignin monomers in a solvent with an in-situ hydrogen donor. This approach has been termed as the Lignin-to-Liquid (LtL) process. It is in fact a thermochemical solvolytic process performed in polar solvents such as water and alcohols at high temperatures and high pressures. In the LtL process, formic acid is used as hydrogen donor, which is converted in situ to molecular hydrogen and $\mathrm{CO} / \mathrm{CO}_{2}$. The reaction product is a mixture of monomeric alkylated phenols and aliphatic hydrocarbons, with a high $\mathrm{H} / \mathrm{C}$ and a low $\mathrm{O} / \mathrm{C}$ ratio. As shown by previous studies, the decomposition of formic acid and the chemical reaction between lignin and formic acid are competing reactions, and therefore, a formylation-eliminationhydrogenolysis mechanism for the formic acid aided lignin conversion has been proposed (Kleinert et al., 2009; Oregui-Bengoechea et al., 2015; Løhre et al., 2017; Oregui-Bengoechea et al., 2017). However, as highlighted in these works, optimization of such a process would be challenging and timeconsuming due to the interactions between different experimental conditions. Nevertheless, there is ongoing research on this approach, and a number of papers have been published addressing subjects such as reaction mechanisms (Holmelid et al., 2012; Oregui-Bengoechea et al., 2017), kinetic modelling (Gasson et al., 2012), and the effect of catalyst to increase energy efficiency (Liguori and Barth, 2011; Oregui-Bengoechea et al., 2015). Most of the reported results have been obtained at small laboratory scale though. In addition, upscaling is necessary to develop the process to industrial level and for the conversion needs to be optimized at larger scales.

Therefore, the aim of this study is to evaluate the product yields and product composition of bio-oils through thermochemical conversion of lignin at a 5-L pilot scale as a function of reaction parameters such as solvent type, level of loading in the reactor, and reaction temperature under stirred and non-stirred conditions. In this study, lignin conversion was investigated at two different temperatures $\left(320\right.$ and $\left.350{ }^{\circ} \mathrm{C}\right)$ using two different reaction solvents (water and ethanol) by changing the stirring rate from $0 \mathrm{rpm}$ to $400 \mathrm{rpm}$ at different levels of loading in the reactor. For the LtL-experiments carried out in this work, a fractional factorial design was set up to determine the impacts of the experimental parameters on yields and product composition as well as to find the conditions leading to highest oil yields and quality.

\section{Materials and Methods}

\subsection{Chemicals}

All reagents and solvents used in this experimental work were purchased from Sigma Aldrich and were used without any further purification $(\geq 98 \%)$. Ethanol, absolute prima, was purchased from Kemetyl Norway AS.

\subsection{Feedstock characterization}

The feedstock used in this work, herein termed as Eucalyptus lignin, was a lignin rich residue isolated through the application of weak acid and enzymatic hydrolysis of Eucalyptus, at the Biorefinery Demo Plant (BDP) located in Örnsköldsvik, Sweden. The lignin content of the feedstock estimated from its elemental composition, was $\sim 50.1 \%$. The ash content of the feedstock was determined to be approximately $4.4 \%$ according to protocol NREL/TP-510-42622 (Sluiter et al., 2008). The H/C and O/C ratios of the feedstock also estimated through elemental analysis, were 1.41 and 0.59 , respectively. The feedstock contained traces of cellulose and hemicellulose, which could explain the high value of the $\mathrm{O} / \mathrm{C}$ ratio compared to that of pure lignin.

Eucalyptus lignin was received as wet sample and was dried in an oven at $60{ }^{\circ} \mathrm{C}$ until constant weight before further grinding and sieving to a dry powder of $<500 \mu \mathrm{m}$ particle size. The dried lignin powder was used as it was without further purification.

\subsection{Lignin to Liquid (LtL) experiments}

\subsubsection{Experimental set-up}

Lignin $(200-350 \mathrm{~g})$, formic acid $(244-427 \mathrm{~g})$, and the solvent $(500-$ $750 \mathrm{~g}$ of water or $394.5-690.4 \mathrm{~g}$ of ethanol) were added to a stirred $5.3 \mathrm{~L}$ 
high-pressure autoclave reactor (ESTANIT GmbH). The autoclave was then closed and heated to the desired temperatures $\left(320-350{ }^{\circ} \mathrm{C}\right)$ with a stirring rate of $0-400 \mathrm{rpm}$ for a reaction time of $2 \mathrm{~h}$. The heating time from room temperature to the desired temperature $\left(320-350{ }^{\circ} \mathrm{C}\right)$ ranged from 60 to 70 min, giving an approximate heating rate of $5^{\circ} \mathrm{C} / \mathrm{min}$. Reaction time $(2 \mathrm{~h})$ was measured in addition to the heating period. The pressure and torque of the stirrer were continuously monitored during the experiments.

The experimental conditions investigated are given in Table 1. The experiments are coded as shown below:

\section{X.Y.Z-T}

$\mathrm{X}$ : Loading in the reactor; $\mathrm{Y}$ : Reaction solvent; $\mathrm{Z}$ : Stirring condition; $\mathrm{T}$ : Reaction temperature

For instance;

L.W.S-320 indicating: Low level of loading Water as reaction solvent. Stirred reaction at $320^{\circ} \mathrm{C}$.

Table 1.

Experimental conditions investigated in the LtL-process experiments.

\begin{tabular}{|c|c|c|c|c|c|c|}
\hline Experiment* & $\underset{\text { (g) }}{\text { Lignin }}$ & $\begin{array}{l}\text { Formic } \\
\text { acid (g) }\end{array}$ & $\begin{array}{l}\text { Water } \\
(\mathrm{g})\end{array}$ & $\underset{(\mathrm{g})}{\text { EtOH }}$ & $\begin{array}{c}\begin{array}{c}\text { Stirrer } \\
\text { speed } \\
(\mathbf{r p m})\end{array} \\
\end{array}$ & $\begin{array}{c}\text { Temperature } \\
\left({ }^{\circ} \mathbf{C}\right)\end{array}$ \\
\hline L.W.S-320 & 191 & 244 & 500 & - & 400 & 320 \\
\hline L.W.NS-320 & 191 & 244 & 500 & - & 0 & 320 \\
\hline H.W.S-320 & 287 & 366 & 750 & - & 400 & 320 \\
\hline H.W.NS-320 & 287 & 366 & 750 & - & 0 & 320 \\
\hline L.W.S-350 & 191 & 244 & 500 & - & 400 & 350 \\
\hline L.W.NS-350 & 191 & 244 & 500 & - & 0 & 350 \\
\hline H.W.S-350 & 287 & 366 & 750 & - & 400 & 350 \\
\hline H.W.NS-350 & 287 & 366 & 750 & - & 0 & 350 \\
\hline L.Et.S-320 & 191 & 244 & - & 394.5 & 400 & 320 \\
\hline L.Et.NS-320 & 191 & 244 & - & 394.5 & 0 & 320 \\
\hline M.Et.S-320 & 335 & 427 & - & 690.4 & 400 & 320 \\
\hline M.Et.NS-320 & 335 & 427 & - & 690.4 & 0 & 320 \\
\hline L.Et.S-350 & 191 & 244 & - & 394.5 & 400 & 350 \\
\hline L.Et.NS-350 & 191 & 244 & - & 394.5 & 0 & 350 \\
\hline M.Et.S-350 & 335 & 427 & - & 690.4 & 400 & 350 \\
\hline M.Et.NS-350 & 335 & 427 & - & 690.4 & 0 & 350 \\
\hline
\end{tabular}

* L: Low loading; H: High loading; M: Maximum loading; W: Water; Et: Ethanol; S: stirred; NS: Non-stirred.

**: Lignin-enriched eucalyptus residue, measured on ash-free basis.

\subsubsection{Work-up procedure}

Upon the completion of the determined reaction time, the reactor heater was turned off and the reactor was cooled to the ambient temperature by flowing cold water through the reactor's cooling coil. The final products of the LtLprocess included a gas phase, a liquid phase, and a solid phase, containing both unreacted starting materials and the char produced during the conversion. Nevertheless, based on the published literature, the bulk of the solid phase produced under the given reaction conditions would be expected to be mainly in the form of char (Gasson et al., 2012). The produced gas was vented by opening the gas-valve. Analysis of the gas composition was not performed as a part of this study, but relevant data for the gas composition can be found in a previous work performed by our group (Oregui-Bengoechea et al., 2015), showing that the decomposition of formic acid was the source of the major part of the gas produced.

After the gas phase was vented, the reactor was opened and the liquid phase was separated from the solid phase. In the water system, the liquid phase consisted of a single aqueous phase while the LtL-oil was adsorbed to the solid phase. The liquid phase was separated from the solid phase by opening the valve on the container bottom. Then, the organic phase was extracted by adding a solution of EtAc:THF (90:10) and subsequently, the solid phase was filtered off.

In the ethanol system, the liquid phase consisted of two immiscible layers; a dark brown LtL-oil phase and a small clear ethanol/water phase. The two layers were separated using the same work-up procedure as in the water system.

The extracted organic phase was dried over $\mathrm{Na}_{2} \mathrm{SO}_{4}$, while the solvent and unreacted ethanol was removed from the LtL-oil using a rotary evaporator at $40{ }^{\circ} \mathrm{C}$ and $250 \mathrm{mbar}$ (in the water system) and $175 \mathrm{mbar}$ (in the ethanol system) to yield a dark brown liquid. The final oil and solid yields were determined by weight after solvent evaporation and drying, respectively. The mass balance was calculated as the sum of $\%$ oil and char yield. The oil fraction was characterized by gas chromatography-mass spectroscopy (GC-MS) and elemental analysis. The chars were characterized by elemental analysis.

\subsection{Elemental analysis}

All samples were analyzed for their elemental composition in the CHNS mode with a Vario EL III instrument using helium as carrier gas. The amount of oxygen was calculated by difference.

\section{5. $G C-M S$}

The LtL-oil (1.0 mg) was dissolved in $1 \mathrm{~mL}$ ethyl acetate:tetrahydrofuran (90:10) and the sample was analyzed using an Agilent Technologies 7890A GC-system with auto-sampler, coupled with an Agilent 5977A MSD. The injection was run in splitless mode at $280{ }^{\circ} \mathrm{C}$ (injector temperature) on a $30 \mathrm{~m} \mathrm{HP}-5 \mathrm{~ms}$ column with $250 \mu \mathrm{m} \mathrm{ID}$ and thickness of $0.25 \mu \mathrm{m}$ from Agilent Technologies. The following GC-MS instrumental conditions were applied:

Start temperature: $40{ }^{\circ} \mathrm{C}$; Heating rate $1: 6^{\circ} \mathrm{C} / \mathrm{min}$; Final temperature 1: $280{ }^{\circ} \mathrm{C}$; Heating rate $2: 40^{\circ} \mathrm{C} / \mathrm{min}$; Final temperature 2: $300{ }^{\circ} \mathrm{C}$; Ion-source temperature for MS: $250^{\circ} \mathrm{C}$; and Mass range: $50-400 \mathrm{u}$.

The GC-MS inter phase valve delay was set to $5 \mathrm{~min}$ and the MS detector was operated in positive mode at $70 \mathrm{eV}$. Compounds were identified using the Enhanced MSD Chemstation software F.01.00.1903 and the NIST 2.0 library.

\subsection{Experimental design}

As mentioned earlier, for the LtL-experiments carried out in this work, a fractional factorial design was set up. Experimental variables, which were studied, were (1) level of loading in the reactor (the sum of input amounts of the reactants), (2) reaction solvent, (3) stirring condition, and (4) reaction temperature. A high $(+)$ and low $(-)$ value for the experimental variables was selected for use in the design. The duration of the experiments was kept constant $(2 \mathrm{~h})$ in both reaction systems. A fractional factorial design $\left(2^{4-1}\right)$ which included a balanced half of all possible combinations of the variables was used to reduce the number of experiments required in each reaction system. An overview of the experimental parameters is tabulated in Table 2.

All the response factors, quantitative yields (\% oil and \% char), $\mathrm{H} / \mathrm{C}$ and $\mathrm{O} / \mathrm{C}$ ratios, $\mathrm{C}$ recovery, $\mathrm{H}$ recovery, and $\mathrm{O}$ recovery from the design were interpreted using principal component analysis (PCA) and Sirius 10.0 software. A biplot of a PCA reveals correlations between loadings/descriptors and their potential association with the same properties of an object. Loadings, which are projected close to each other with respect to the origin, are positively correlated, while loadings, which are projected oppositely to each other, are negatively correlated. Loadings that have a strong influence on the model will be projected far from the origin, and loadings with negligible or minor influence on the model will appear close to the origin in the biplot (Carlson and Carlson, 2005).

In many cases, principal components are not the ideal latent variables. Partial Least Squares (PLS) regression analysis is a method that can establish quantitative relations between two blocks of data, e.g., a block consisting of descriptor data for a series of reaction systems and a block 
consisting of response data measured on these systems (Carlson and Carlson, 2005). In line with that, such regression analysis was applied to each yield variable in the data set.

Table 2.

Experimental details of the LtL-process experiments: Variable $1(-)=$ low loading $(\mathrm{g})$, Variable $1(+)=$ high or maximum loading, Variable $2(-)=$ water, Variable $2(+)=$ ethanol Variable $3(-)$ $=0 \mathrm{rpm}$, Variable $3(+)=400 \mathrm{rpm}$, Variable $4(-)=320^{\circ} \mathrm{C}$, Variable $4(+)=350^{\circ} \mathrm{C}$

\begin{tabular}{|c|c|c|c|c|}
\hline Experiment & $\begin{array}{c}\text { Loading water-/ethanol- } \\
\text { system } \\
\left(\begin{array}{c}\text { Lignin + solvent + FA } \\
(\mathrm{g}))\end{array}\right. \\
\end{array}$ & $\begin{array}{c}\text { Solvent } \\
\text { type }\end{array}$ & $\begin{array}{c}\text { Speed of } \\
\text { stirrer } \\
(\mathbf{r p m})\end{array}$ & $\begin{array}{c}\text { Temperature } \\
\left({ }^{\circ} \mathbf{C}\right)\end{array}$ \\
\hline L.W.S-320 (- - + -) & 935 & Water & 400 & 320 \\
\hline L.W.NS-320 (- - - -) & 935 & Water & 0 & 320 \\
\hline H.W.S-320 (+- + -) & 1403 & Water & 400 & 320 \\
\hline H.W.NS-320 (+ - - -) & 1403 & Water & 0 & 320 \\
\hline L.W.S-350 $(--++)$ & 935 & Water & 400 & 350 \\
\hline L.W.NS-350 (- - - +) & 935 & Water & 0 & 350 \\
\hline H.W.S-350 $(+-++)$ & 1403 & Water & 400 & 350 \\
\hline H.W.NS-350 (+ - - +) & 1403 & Water & 0 & 350 \\
\hline L.Et.S-320 (- + +-) & 830 & Ethanol & 400 & 320 \\
\hline L.Et.NS-320 (- + - -) & 830 & Ethanol & 0 & 320 \\
\hline M.Et.S-320 $(+++-)$ & 1452 & Ethanol & 400 & 320 \\
\hline M.Et.NS-320 (++ - -) & 1452 & Ethanol & 0 & 320 \\
\hline L.Et.S-350 $(-+++)$ & 830 & Ethanol & 400 & 350 \\
\hline L.Et.NS-350 (- +- +) & 830 & Ethanol & 0 & 350 \\
\hline M.Et.S-350 $(++++)$ & 1452 & Ethanol & 400 & 350 \\
\hline M.Et.NS-350 $(++-+)$ & 1452 & Ethanol & 0 & 350 \\
\hline
\end{tabular}

\section{Results and Discussion}

\subsection{Product yields}

The quantitative results of all the LtL-process experiments are presented in Figure 1 and TableS1 in the supplementary material.

For the water-based experiments, it was not possible to use the maximum level of loading due to pressure limitations, and thus, the results from waterbased experiments with high loading level would not be completely comparable with the results of the ethanol-based experiments with maximum loading level.

The feedstock used in this work was not directly soluble in the reaction media at low temperatures, and thus, the initial state of the reaction system was a suspension of lignin particles in the liquid reaction medium. Further heating melted the lignin and increased the solubility. The physical state of the reaction system at the selected temperatures was not explicitly known, but torque readings during the heating period indicated that lignin melted into a viscous liquid, which dissolved at higher temperatures.

\subsubsection{Variation in yields as a function of different loadings in the reactor}

In the first part of this work, the effect of two different levels of loading on product yield was considered. The yields of oil (wt.\%) and char wt.\%), together with the lignin mass balance (\%), for all the experiments are shown in Figure 1a. The difference between two consecutive experiments, presented in Figure 1a, was the degree of filling in the reactor while all the other conditions were kept constant.

The yields of oil and char ranges, respectively, from 18 to $72 \%$ and from 9 to $36 \%$ by weight of the lignin input. The amount of the original lignin mass recovered as oil and char was calculated as lignin mass balance and was in the range $47-81 \%$ relative to lignin input weight. The difference between the input and the measured mass balance would comprise gas phase and aqueous products, which were produced in the thermal decomposition reactions Since a precise mass balance of all products was difficult to obtain, the carbon recovery data presented in Section 3.2 could be more pertinent for an overall evaluation of yields.

The results showed that increasing the loading in the reactor from a low to a high/maximum level, when all other reaction conditions were kept constant, led to an increase in bio-oil yield percentage. The increased oi yield could be associated with a higher overall conversion due to more efficient stirring and higher operating pressure when the reactor was loaded to a high level (see Table S1). The reactor was equipped with two stirrers above each other on the stirring rod, and thus, the different filling levels in the reactor were one of the main factors for investigating changes in product yields as a function of two simultaneously rotating stirrers. The results also showed that when the maximum level of the reactor was loaded, rotation of both stirrers would result in a more efficient mixing of lignin with the reaction medium and consequently, better lignin de-polymerization. As mentioned above, the pressure in the reactor was proportional with the level of loading, and in particular with liquid level (formic acid and reaction solvent), in the reactor. That means that increasing the amount of reaction media would increase the pressure during the reaction, which might also increase the reaction efficiency. A maximum difference of $20 \%$ in oil yield was observed as a function of the reactor filling, while the char yields tended to decrease when increasing the level of loading. The reaction was optimal when a high amount of oil and a low amount of char was produced so high loading levels were found preferable.

\subsubsection{Variation in yields as a function of solvent type}

The effect of reaction solvent on product yields was considered by replacing water with ethanol as reaction solvent. The two successive experiments differed from each other in terms of the type of reaction solvent while all the other reaction parameters were kept constant.

For the ethanol experiments, as shown in Figure $1 \mathrm{~b}$, the oil yields were significantly higher than for the water-based experiments, except for the maximum loaded, non-stirred experiment at $350{ }^{\circ} \mathrm{C}$. The yields were in a range of $18-55 \%$ and $31-72 \%$ for water- and ethanol-based experiments, respectively. In terms of the char yield, it can be observed that the ethanolbased experiments yielded higher amounts of char than the water-based experiments, except in low loaded, stirred experiment at $320^{\circ} \mathrm{C}$. Moreover, a better mass balance was achieved for all the ethanol-based experiments As mentioned above, the main reason for this might be the lack of data on aqueous products when using water as solvent.

\subsubsection{Variation in yields as a function of stirring condition}

Figure 1c presents a comparison of mass yields (\%) among all the experiments based on their differences in stirring condition. The two consecutive experiments presented in Figure 1c were performed at the same reaction conditions, while the rate of stirring was changed from 400 $\mathrm{rpm}$ to the non-stirred condition (0 rpm).

The general observation was that the oil yields, which were obtained at the stirred conditions, were consistently much higher than those recorded at the non-stirred conditions. The results showed that the difference in oil yields ranged from 12 to 33 wt. \% of the lignin input between the stirred and non-stirred experiments. Furthermore, the char formation was shown to be significantly decreased by stirring when all the other reaction parameters were kept constant. The overall result revealed that at the stirred conditions, both water and ethanol-based experiments yielded over 40 wt.\% oil, regardless of the level loaded in the reactor. However, ethanol-based experiments with a high level of loading in the reactor at the stirred conditions led to the highest bio-oil yields.

\subsubsection{Variation in yields as a function of reaction temperature}

The purpose of this part of the work was to compare the product yields recorded for the experiments performed at different reaction temperatures. Figure $1 \mathrm{~d}$ shows an overview of the mass yield $(\%)$ for all the experiments in which the only difference between the two successive experiments was the operating temperature. Experiments were run using two different 
Ghoreishi et al. / Biofuel Research Journal 21 (2019) 937-946

941
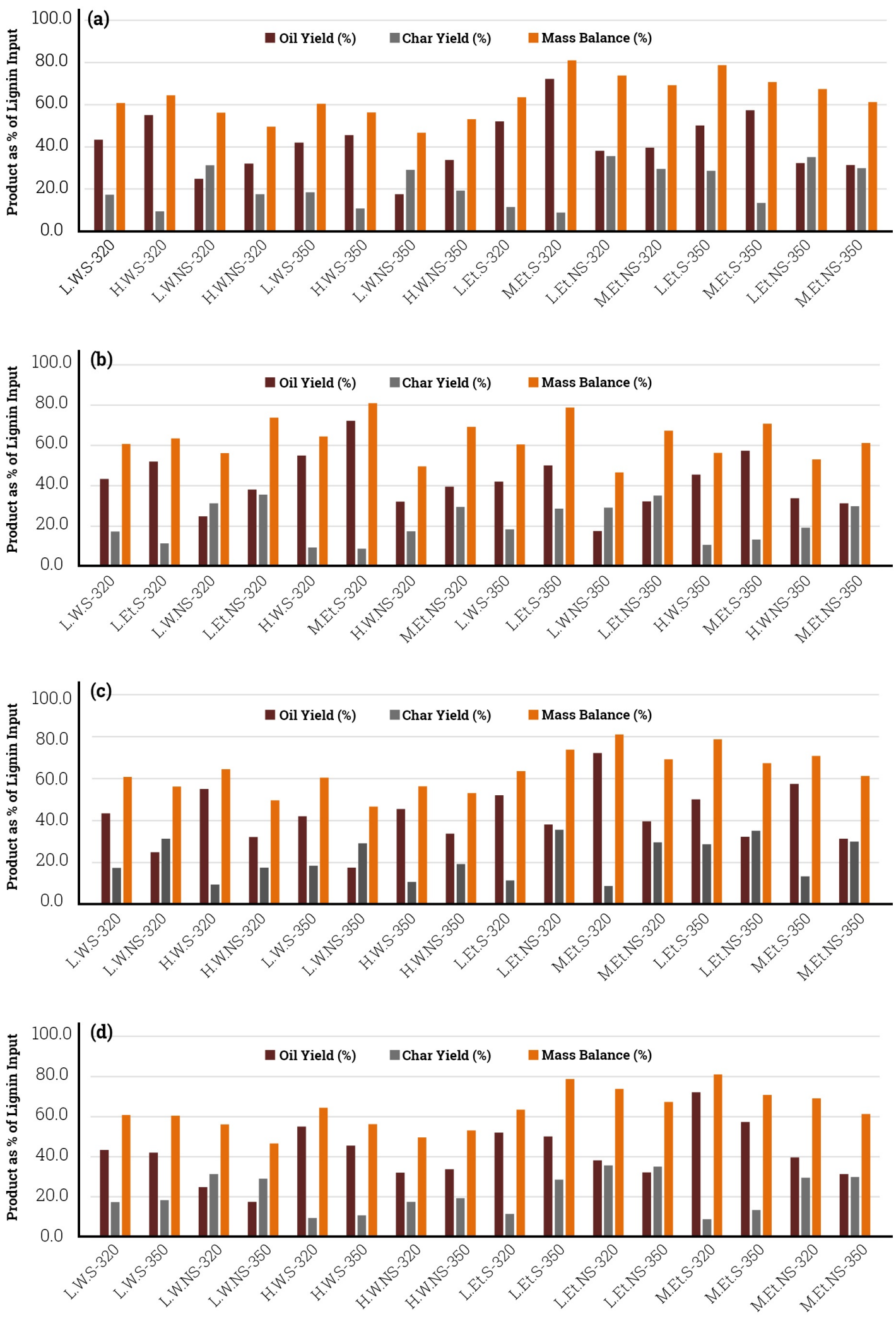

Fig. 1. Oil yield (wt.\%), char yield (wt.\%), and lignin mass balance (\%) given as percentages of lignin input plotted according to different (a) levels of loading in the reactor (b) solvent types (c) stirring conditions, and (d) reaction temperatures (For coding; see Table 1).

Please cite this article as: Ghoreishi S., Barth T., Derribsa H. Stirred and non-stirred lignin solvolysis with formic acid in aqueous and ethanolic solvent systems at different levels of loading in a 5-L reactor. Biofuel Research Journal 21 (2019) 937-946. DOI: 10.18331/BRJ2019.6.1.5 
temperatures $\left(320\right.$ and $350{ }^{\circ} \mathrm{C}$ ), while all the other reaction parameters were kept constant.

The results showed a trend of slightly decreasing oil yields with temperature. The decreasing trend was more marked in the experiments performed at the stirred conditions with a high level of loading in the reactor. The char yields were not significantly influenced by the reaction temperature, showing a slight increase by elevating the temperature from $320^{\circ} \mathrm{C}$ to $350{ }^{\circ} \mathrm{C}$. The trends of the results obtained for the two solvent systems were quite similar at both temperatures. The experiments performed at $320{ }^{\circ} \mathrm{C}$ with high level of filling in the reactor under the stirred conditions led to over $55 \mathrm{wt} . \%$ oil regardless of the solvent type.

\subsection{Elemental analysis and carbon balance}

Figure 2 displays a Van Krevelen plot of $\mathrm{H} / \mathrm{C}$ and $\mathrm{O} / \mathrm{C}$ ratios for all the LtLoils and the lignin feedstock. Deoxygenation was clear for all the 16 bio-oils since the $\mathrm{O} / \mathrm{C}$ ratio of the LtL-oils was significantly reduced relative to the starting biomass (Eucalyptus lignin). However, in bulk, hydrogenation did not seem to have occurred since the $\mathrm{H} / \mathrm{C}$ ratio of the bio-oils was also reduced relative to the starting material. This could in part be explained by the conversion of the carbohydrate residues to aqueous products. For lignin, in the LtL-process, hydrogen can both be added and lost. The highly reactive in situ formed hydrogen from the thermal decomposition of formic acid is responsible for converting the lignin constituents into hydrogen-rich, oxygen-depleted products. However, hydrogen can also be removed as aqueous products when hydroxyl groups are cleaved from lignin structure. Since the carbon content $(\%)$ of the bio-oils produced in this work increased relative to the carbon content (\%) of the starting raw material (Eucalyptus lignin), it is unlikely that hydrogen which is bound to carbon, was removed as alcohol and/or aldehyde during the LtL-process (Kleinert and Barth, 2008; Holmelid et al., 2012). The H/C value was in the range of $1.15-1.44$, suggesting that aromatic rings could be predominant. The general observation was that bio-oils from the water-based experiments had the lowest $\mathrm{O} / \mathrm{C}$ indicating a higher degree of deoxygenation. However, bio-oils from the ethanol-based experiments were shown to have the highest $\mathrm{H} / \mathrm{C}$ ratios indicating a higher degree of hydrogenation.

Figure 2 shows that for the water-based experiments, the highest $\mathrm{H} / \mathrm{C}$ values were obtained in the stirred experiments performed at $350{ }^{\circ} \mathrm{C}$ regardless of the level of loading (Exp. L.W.S-350 and H.W.S-350), thus indicating that higher reaction temperature together with stirring contributed to a more efficient hydrogenation of lignin constituents. All the bio-oils produced at the nonstirred conditions showed a slight decrease in both $\mathrm{H} / \mathrm{C}$ and $\mathrm{O} / \mathrm{C}$ values compared to the bio-oils produced at the stirred conditions at the same temperature and level of loading. This indicated a higher degree of dehydrogenation and deoxygenation in the non-stirred experiments.

In addition, Figure 2 depicts that replacing water with ethanol as reaction solvent while keeping the other reaction parameters constant, led to a clear

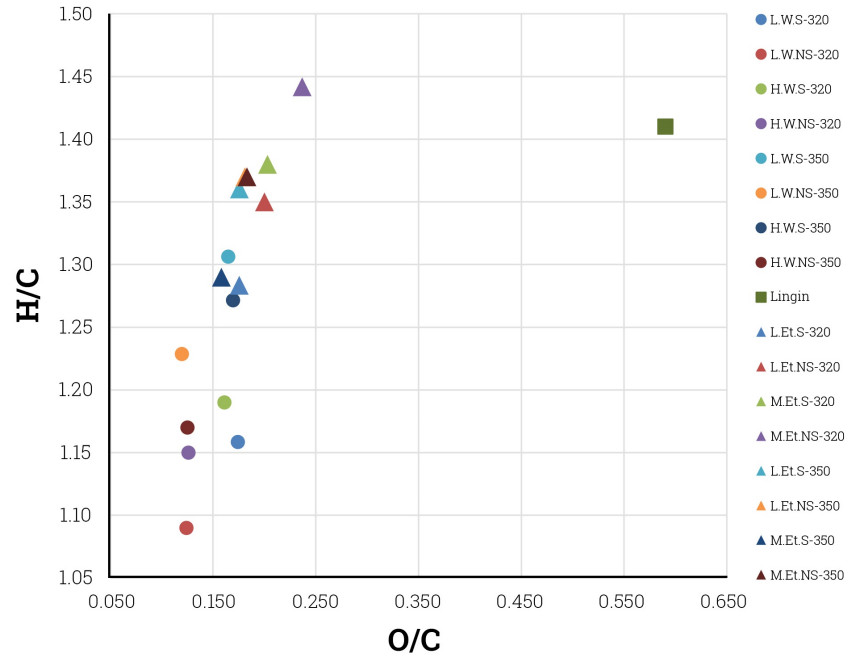

Fig. 2. Van Krevelen plot showing $\mathrm{H} / \mathrm{C}$ ratio and $\mathrm{O} / \mathrm{C}$ ratio of the LtL-oils and lignin.

increase in both $\mathrm{H} / \mathrm{C}$ and $\mathrm{O} / \mathrm{C}$ ratios for the bio-oils. Previous investigations revealed that the higher degree of hydrogenation in ethanol-systems was due to the substitution of ethyl groups on the aromatic ring structures, which would increase the number of alkyl units in the product and thus, increase the $\mathrm{H} / \mathrm{C}$ ratio (Holmelid et al., 2012). However, among the bio-oils produced in the ethanol-based system, the bio-oil associated with the experiment M.Et.NS-320 had the highest $\mathrm{H} / \mathrm{C}$ and $\mathrm{O} / \mathrm{C}$ values. Since neither the $\mathrm{H} / \mathrm{C}$ nor the $\mathrm{O} / \mathrm{C}$ ratios of the bio-oils of the ethanol-based experiments followed a clear trend, it was not possible to draw a specific conclusion. Furthermore, Figure 2 reveals that the $\mathrm{H} / \mathrm{C}$ and $\mathrm{O} / \mathrm{C}$ values of the bio-oils produced in the experiments H.W.S-350 and M.Et.S-350 were quite similar even though they were produced in two different reaction systems.

The elemental compositional data also made it possible to calculate the yields on a carbon basis in addition to the recovery by weight. Table 3 tabulates the carbon recovery data from all the LtL-process experiments carried out in this work. The carbon recovery data were calculated using input of carbon in the form of lignin and output of carbon in the form of organic products (bio-oils and chars). Therefore, the recovery of carbon in the products would be dependent on the product recovery by weight. A

Table 3.

Carbon recovered in bio-oil and char of the LtL-process experiments.

\begin{tabular}{|c|c|c|c|c|c|c|c|c|}
\hline Experiment & L.W.S-320 & L.W.NS-320 & H.W.S-320 & H.W.NS-320 & L.W.S-350 & L.W.NS-350 & H.W.S-350 & H.W.NS-350 \\
\hline Carbon added as lignin (g) & 95.84 & 95.84 & 143.76 & 143.76 & 95.84 & 95.84 & 143.76 & 143.76 \\
\hline Carbon recovered in oil (\%) & 64.42 & 39.04 & 82.87 & 50.18 & 62.59 & 27.56 & 67.51 & 52.87 \\
\hline Carbon recovered in char $(\%)$ & 20.02 & 41.36 & 9.29 & 22.71 & 24.63 & 39.96 & 11.10 & 24.33 \\
\hline Total carbon recovered $(\%)$ & 84.44 & 80.40 & 92.16 & 72.89 & 87.22 & 67.52 & 78.61 & 77.20 \\
\hline Experiment & L.Et.S-320 & L.Et.NS-320 & H.Et.S-320 & H.Et.NS-320 & L.Et.S-350 & L.Et.NS-350 & H.Et.S-350 & H.Et.NS-350 \\
\hline Carbon added as lignin (g) & 95.84 & 95.84 & 167.72 & 167.72 & 95.84 & 95.84 & 167.72 & 167.72 \\
\hline Carbon recovered in oil (\%) & 76.51 & 54.49 & 102.68 & 54.33 & 73.83 & 46.81 & 85.79 & 45.47 \\
\hline Carbon recovered in char $(\%)$ & 13.95 & 51.99 & 8.78 & 43.03 & 41.11 & 52.37 & 16.10 & 43.55 \\
\hline Total carbon recovered $(\%)$ & 90.46 & 106.48 & 111.46 & 97.36 & 114.94 & 99.18 & 101.89 & 89.02 \\
\hline
\end{tabular}

* All calculations are carried out on ash free basis 

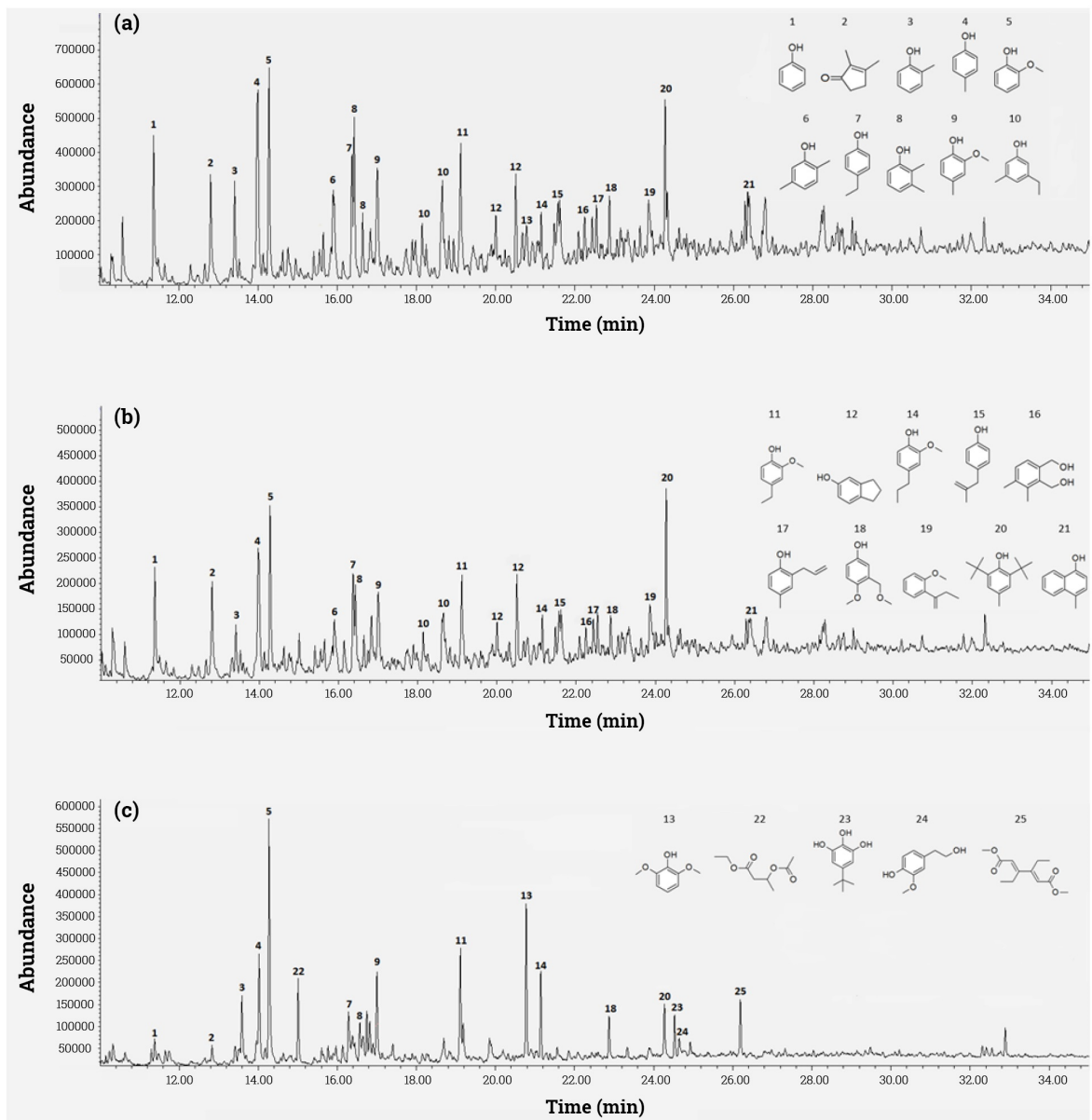

(d)

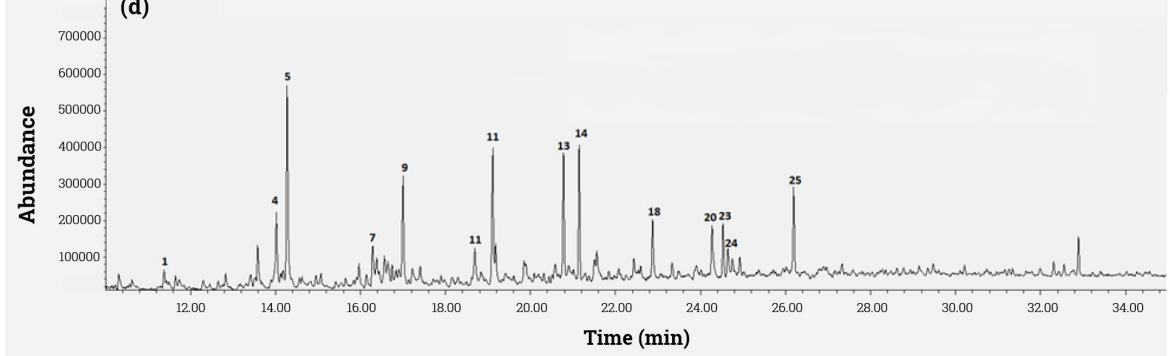

(e)

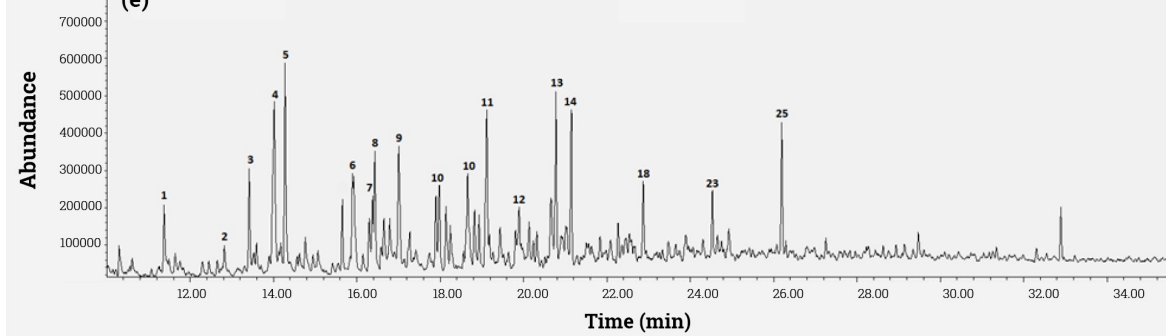

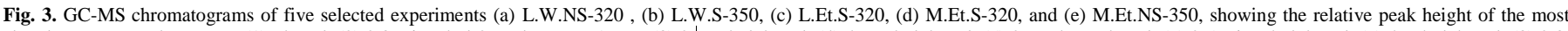

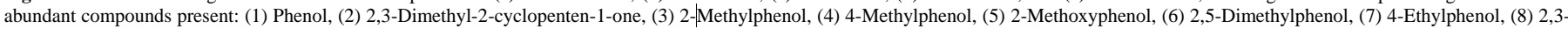
Dimethylphenol, (9) 2-Methoxy-4-methylphenol, (10) 3-Ethyl-5-methylphenol, (11) 4-Ethyl-2-methoxyphenol, (12) 2,3-Dihydro-1H-inden-5-ol, (13) 2,6-Dimethoxyphenol, (14) 2-Methoxy-4propylphenol, (15) p-(2-Methylallyl) phenol, (16) 6-Hydroxymethyl-2,3-dimethylphenyl methanol, (17) 2-Allyl-4-methylphenol, (18) 4-Methoxy-3-methoxymethylphenol, (19) o-(1-Ethylvinyl)

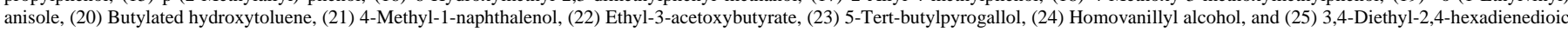
acid dimethyl ester. 
major source of uncertainty was the lack of data for aqueous products and gases produced from the lignin. However, unpublished results suggested that the aqueous products were methanol, short chain organic acids, furfural from carbohydrate residues, etc. The recovery figures were thus most useful for comparative use. Calculations showed a carbon recovery ranging from 68 to $92 \%$ for the water-based experiments, and a carbon recovery ranging from 89 to $115 \%$ for the ethanol based experiments. The incorporation of ethyl groups from ethanol contributed to the high carbon recovery compared to the lignin carbon input in the products of the ethanol-based experiments. Furthermore, a higher amount of carbon was recovered in the stirred experiments compared to the non-stirred ones (except Exp. L.Et.S-320) which may be explained by increased gasification at non-stirred conditions due to high temperature at the reactor walls above the solvent level. There was no clear trend showing reduction or increase in carbon recovery, neither with the level of loading in the reactor nor when the reaction temperature was changed. The elemental composition of all the bio-oil and char samples, including $\mathrm{H} / \mathrm{C}$ and $\mathrm{O} / \mathrm{C}$ ratios, are presented in Table $\mathrm{S} 2$.

\subsection{Molecular composition of bio-oils identified with $G C-M S$}

The LtL-oils comprised a complex mixture of phenolic compounds. Figure 3 shows the chromatograms of five selected bio-oils. The volatile monomeric phenols were identified using GC-MS library search. The chromatograms presented in Figure 3 show that the composition of the bio-oils were quite similar in different oil samples from the same solvent system, while the abundance of each component varied when the other reaction conditions were changed. However, the compositional differences were more significant when comparing oils from the water- and ethanol-based systems (Figs. 3a and b vs. Figs. 3c, d , and e).

A general observation was that 2-Methoxyphenol (Guaiacol) was the most abundant compound in almost all of the chromatograms depicted in Figure 3, while the proportion of the other compounds varied relative to this compound in the bio-oils produced at different reaction conditions. The GC-MS chromatograms depicted in Figure 3a and b indicate that the bio-oils produced in the water-based system, consisted mainly of alkylated phenols in high concentrations. More specifically, phenol, 2,3-dimethyl-2-cyclopenten-1-one, methyl- and ethylphenol, guaiacol, allylphenol, and butylated hydroxytoluene were the most abundant compounds identified. Identification of the most abundant peaks in the chromatograms related to the ethanol-based experiments showed a higher amount of methoxy-substituted phenols such as 2,6dimethoxyphenol, 2-methoxy-4-propylphenol, 4-methoxy-3methoxymethylphenol, and 5-tert-butylpyrogallol, corresponding to a significantly higher $\mathrm{O} / \mathrm{C}$ ratio (Figure 2) and a higher average molecular weight in the oils obtained from this solvent system compared to the bio-oils associated with the water-based system. 3,4-diethyl-2,4-hexadienedioic acid dimethyl ester was also one of the most abundant compounds in bio-oils generated in the ethanol-based system which was possibly a condensations product of the ethanol in the reaction solvent.

The lower content of oxygen in the bio-oils of the water-based system resulted in lower $\mathrm{O} / \mathrm{C}$ ratios of the oils, corroborating the results of the elemental analysis (Figure 2), while the higher degree of alkyl-substitution in the oils generated in the water-based system did not result in higher $\mathrm{H} / \mathrm{C}$ ratios compared to the bio-oils of the ethanol-based system. This could be explained by the fact that only the volatile fraction of the bio-oils could be analyzed by GC-MS, and since the composition of the heavier portion of the oils was unknown, it was not possible to have a specific conclusion when it came to $\mathrm{H} / \mathrm{C}$ ratio.

Water as a solvent is undoubtedly cheaper and more readily available relative to ethanol. However, in the LtL-process, ethanol has been found to be better suited as reaction solvent since it could act both as a solvent and as a reactant (Holmelid et al., 2012). Products produced in ethanol-based experiments were considered to be more useful in large-scale production of biooils and/or chemicals. Therefore, ethanol appeared to be more economically viable in terms of industrial investment in product quality and application. One may also propose isopropanol as solvent. However, since isopropanol is even more expensive than ethanol, it does not seem to be economically beneficial.

\subsection{Principal component analysis (PCA)}

In the defined experimental setup presented in Table 2, the following parameters were studied: oil yield $(\%)$, char yield $(\%), \mathrm{H} / \mathrm{C}$ ratio and $\mathrm{O} / \mathrm{C}$ ratio of the bio-oils, and carbon recovery (\%).

Figure 4 depicts a biplot of the experimental design using the design variables and all the experimental responses. All data were standardized, meaning that all values for each variable were weighted by division with the standard deviation. Standardization led to an equal variance from -1 to +1 for each variable.

The PCA confirmed that the oil yield (\%) was highly correlated with the speed of stirring and a high level of loading in the reactor. Furthermore, there was a positive correlation between carbon balance $(\%)$ with oil $(\%)$ and char (\%) yields, respectively, on PC1 and PC2. This implied that the highest carbon recovery with the lowest loss of lignin-derived carbon into aqueous and gas-phase products, was achieved in the experiments with the highest product yields (oil and char yields). The design also confirmed that both oil (\%) and char (\%) yields were positively correlated with the solvent type, again confirming the observation that the ethanol-based reactions led to higher oil and char yields, and thus, higher carbon recovery compared to the water-based reactions. In addition, a positive correlation between the solvent type and $\mathrm{H} / \mathrm{C}$ and $\mathrm{O} / \mathrm{C}$ ratios was also observed on $\mathrm{PC} 1$, which again confirmed the results obtained in the elemental analysis (i.e., the bio-oils of the ethanol-based experiments had higher $\mathrm{H} / \mathrm{C}$ and $\mathrm{O} / \mathrm{C}$ ratios compared to the bio-oils of the water-based experiments). A strong positive correlation between the experiment M.Et.NS-320 and $\mathrm{H} / \mathrm{C}$ and $\mathrm{O} / \mathrm{C}$ ratios was also shown, corresponding to the $\max \mathrm{H} / \mathrm{C}$ and $\mathrm{O} / \mathrm{C}$ ratios shown in Figure 2.

Furthermore, the oil yield (\%) and carbon balance (\%) were negatively correlated with the reaction temperature and positively correlated with the stirring and level of loading, matching the results obtained in Sections 3.1.1-3.1.4 (i.e., the stirred reaction performed at $320^{\circ} \mathrm{C}$ with high level of loading in the reactor led to high oil yields, and thus, high carbon recovery). However, the char yield (\%), which is described on PC2, was positively correlated with the reaction temperature and $\mathrm{H} / \mathrm{C}$ ratio. This could be caused by a disproportionation of oil components to carbon-rich char and hydrogen-enriched liquid product at higher temperatures. The negative correlation between the char yield $(\%)$ and the level of loading in the reactor and stirring condition confirmed the observations of the positive effects of high reactor loading presented and discussed in Sections 3.1.1 and 3.1.3.

From the PLS analysis and the respective regression coefficients, it could be seen that the design variables were used to calculate multivariate regression models for the yields. The regression equations for the oil and char yields, $\mathrm{H} / \mathrm{C}$ and $\mathrm{O} / \mathrm{C}$ ratios, and carbon balance (\%), which were well modelled and well predicted, are given in Table 4. For the other variables, models with a significant uncertainty and a considerable degree of scatter were produced. This implied that a larger design would be needed for reliable yield predictions, since only linear relationships could be well described in the screening model based on the factorial design.

Both oil and char yields were well explained by the model when all four variables were taken into account. According to the fitted equations, high level of loading and high speed of stirrer increased the oil yield and decreased the char yield, while high reaction temperature decreased the oil yield and increased the char yield. Ethanol as reaction solvent led to an increase in both oil and char yields. Moreover, the model provided a reasonable explanation for carbon recovery (\%) using all the relevant variables. The regression equations in Table 4 show that there was a significant positive correlation between the carbon recovery (\%) with stirring of the reaction and usage of ethanol as reaction solvent. The $\mathrm{H} / \mathrm{C}$ ratio of the bio-oils was well modelled and well predicted when the experiments were categorized based on the reaction temperature. According to the regression equations shown, the $\mathrm{H} / \mathrm{C}$ ratio of the oils (based on the experiments performed at $320^{\circ} \mathrm{C}$ ) was increased when the reactor was loaded at the high level and ethanol was used as reaction solvent, while it was not influenced by the stirring condition in particular. The model best explained the $\mathrm{O} / \mathrm{C}$ ratio of the oils when only the non-stirred experiments were taken into account. The fitted equations in Table 4 also show that the $\mathrm{O} / \mathrm{C}$ ratio of the bio-oils had a strong positive correlation with 


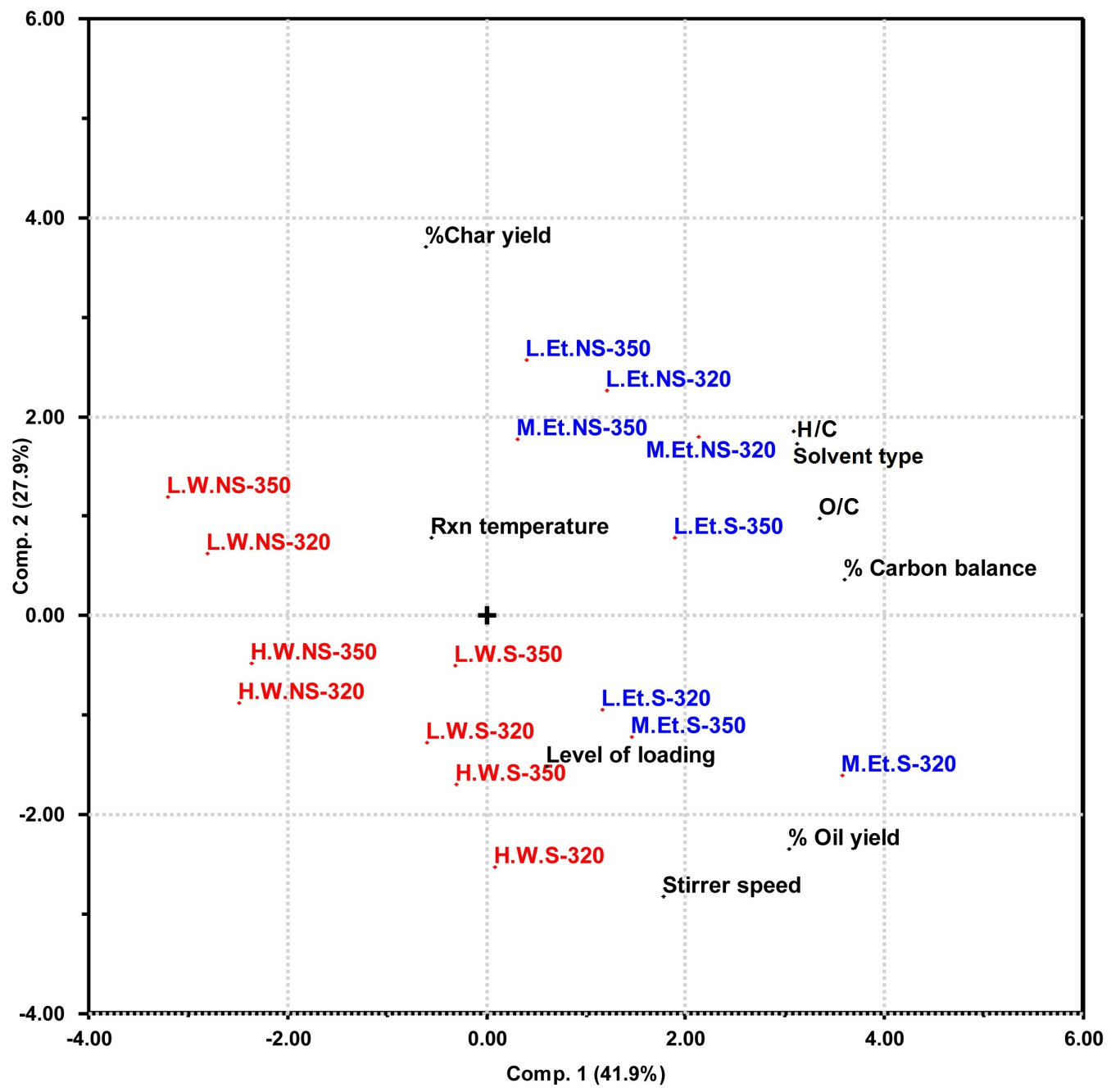

Fig. 4. Biplot for Principal Component Analysis (PCA) of the data set consisting of experimental variables and response factors.

Table 4.

Fitted regression equations for the oil and char yields (\%), $\mathrm{H} / \mathrm{C}$ and $\mathrm{O} / \mathrm{C}$ ratios, and carbon recovery (\%) using standardized design variable values.

\begin{tabular}{lccccccc}
\hline Equation for & $\mathbf{k}$ & Loading & Stirrer speed & Experiental temperature & Solvent & Prediction* & Correlation $(\mathbf{R})$ \\
\hline \% Oil yield & 3.06 & 0.32 & 0.80 & -0.22 & 0.37 & $92.4 \%$ & 0.96 \\
\% Char yield & 2.27 & -0.46 & -0.74 & 0.16 & 0.27 & $85.8 \%$ & 0.93 \\
\% Carbon recovery & 6.42 & -0.01 & 0.39 & -0.16 & 0.77 & $77.2 \%$ & 0.88 \\
H/C ratio & 10.4 & 0.28 & -0.06 & - & 0.92 & $92.5 \%$ & 0.96 \\
O/C ratio & 3.66 & 0.14 & - & -0.24 & 0.92 & $96.1 \%$ & 0.96 \\
\hline
\end{tabular}

* Indicates variance (\%) which is explained by the model.

solvent type, a weak positive correlation with level of loading, and a negative correlation with reaction temperature. This confirms the systematic effect of the variables and the fact that the bio-oil produced in the ethanol-based experiment under non-stirred condition at $320{ }^{\circ} \mathrm{C}$ with high level of loading in the reactor had the highest $\mathrm{O} / \mathrm{C}$ values.

\section{Conclusions}

This study was aimed at providing an insight into the yield and composition of the products generated through an LtL-process using a 5-L pilot scale at different reaction conditions. The maximum difference in biooil yields of the experiments performed in this work was above $50 \%$. 
The main conclusions drawn include:

- $\quad$ Ethanol-based experiments yielded the highest amounts of bio-oil with the highest $\mathrm{H} / \mathrm{C}$ and $\mathrm{O} / \mathrm{C}$ ratios;

- $\quad$ Stirred reactions led to higher bio-oil yields, lower char yields, and higher carbon recovery compared to non-stirred reactions;

- Increased level of loading in the reactor led to an increase in bio-oil yield and a decrease in char yield.

- Guaiacol (2-Methoxyphenol) was the major component in most of the $\mathrm{LtL}$ oils produced in both solvent systems regardless of the other reaction conditions.

- The highest bio-oil yield and lowest char yield were obtained through the ethanol-based experiment performed under stirring at $320{ }^{\circ} \mathrm{C}$ with high level of loading in the reactor (i.e., Exp. M.Et.S-320).

Overall, the use of the 5-L pilot scale reactor was found very promising, as the highest yields of bio-oil were obtained at stirred, high loading conditions. It should be emphasized that such conditions could not be tested at small laboratory scale experiments.

\section{Acknowledgements}

We gratefully acknowledge LtLNOR, The Norwegian Research Council (grant no. 190965/S60) and Statoil As for financial support and the use of the 5-L reactor. The authors would also like to thank I. J. Fjellanger for assisting with elemental analysis and Sekab for providing lignin.

\section{References}

[1] Azadi, P., Inderwildi, O.R., Farnood, R., King, D.A., 2013. Liquid fuels, hydrogen and chemicals from lignin: a critical review. Renew. Sust. Energy Rev. 21, 506-523

[2] Bu, Q., Lei, H., Zacher, A.H., Wang, L., Ren, S., Liang, J., Wei, Y., Liu, Y., Tang, J., Zhang, Q., Ruan, R., 2012. A review of catalytic hydrodeoxygenation of lignin-derived phenols from biomass pyrolysis. Bioresour. Technol. 124, 470-477.

[3] Carlson, R., Carlson, J.E., 2005. Design and optimization in organic synthesis. Elsevier, Amsterdam, The Netherlands. 24.

[4] Cherubini, F., 2010. The biorefinery concept: using biomass instead of oil for producing energy and chemicals. Energy Convers. Manage. 51(7), 1412-1421.

[5] Cherubini, F., Jungmeier, G., 2010. LCA of a biorefinery concept producing bioethanol, bioenergy, and chemicals from switchgrass. Int. J. Life Cycle Assess. 15(1), 53-66.

[6] Creutzig, F., Ravindranath, N.H., Berndes, G., Bolwig, S., Bright, R., Cherubini, F., Chum, H., Corbera, E., Delucchi, M., Faaji, A., Fargione, J., Haberl, H., Heath, G., Lucon, O., Pelvin, R., Popp, A., RobledoAbad, C., Rose, S., Smith, P., Stormmans, A., Suh, S., Masera, O., 2015. Bioenergy and climate change mitigation: an assessment. GCB Bioenergy. 7(5), 916-944

[7] Gasson, J.R., Kleinert, M., Barth, T., Forchheim, D., Sahin, E., Kruse, A., Eide, I., 2010. Lignin solvolysis: upscaling of the Lignin-to-Liquid conversion process towards technical applicability. The 18th European Biomass Conference and Exhibition, Lyon, France. 3-12.

[8] Gasson, J.R., Forchheim, D., Sutter, T., Hornung, U., Kruse, A., Barth, T., 2012. Modeling the lignin degradation kinetics in an ethanol/formic acid solvolysis approach. part 1. kinetic model development. Ind. Eng. Chem. Res. 51(32), 10595-10606.

[9] Gerber, L., Gassner, M., Maréchal, F., 2011. Systematic integration of LCA in process systems design: application to combined fuel and electricity production from lignocellulosic biomass. Comput. Chem. Eng. 35(7), 1265-1280

[10] Gerssen-Gondelach, S.J., Saygin, D., Wicke, B., Patel, M.K., Faaij, A.P.C., 2014. Competing uses of biomass: assessment and comparison of the performance of bio-based heat, power, fuels and materials. Renew. Sust. Energy Rev. 40, 964-998.

[11] Holmelid, B., Kleinert, M., Barth, T., 2012. Reactivity and reaction pathways in thermochemical treatment of selected lignin-like model compounds under hydrogen rich conditions. J. Anal. Appl. Pyrolysis. $98,37-44$.
[12] Kim, J.Y., Oh, S., Hwang, H., Cho, T.S., Choi, I.G., Choi, J.W., 2013. Effects of various reaction parameters on solvolytical depolymerization of lignin in sub- and supercritical ethanol. Chemosphere. 93(9), 1755-1764.

[13] Kleinert, M., Barth, T., 2008. Towards a lignincellulosic biorefinery: direct one-step conversion of lignin to hydrogenenriched biofuel. Energy Fuels. 22(2), 1371-1379.

[14] Kleinert, M., Gasson, J.R., Barth, T., 2009. Optimizing solvolysis conditions for integrated depolymerisation and hydrodeoxygenation of lignin to produce liquid biofuel. J. Anal. Appl. Pyrolysis. 85(1-2), $108-117$

[15] Kristianto, I., Limarta, S.O., Lee, H., Ha, J.M., Suh, D.J., Jae, J., 2017. Effective depolymerization of concentrated acid hydrolysis lignin using a carbon-supported ruthenium catalyst in ethanol/formic acid media. Bioresour. Technol. 234, 424-431.

[16] Liguori, L., Barth, T., 2011. Palladium-Nafion SAC-13 catalysed depolymerisation of lignin to phenols in formic acid and water. J Anal. Appl. Pyrolysis. 92(2), 477-484

[17] Liu, W.J., Jiang, H., Yu, H.Q., 2015. Thermochemical conversion of lignin to functional materials: a review and future directions Green Chem. 17(11), 4888-4907.

[18] Løhre, C., Barth, T., Kleinert, M., 2016. The effect of solvent and input material pretreatment on product yield and composition of biooils from lignin solvolysis. J. Anal. Appl. Pyrolysis. 119, 208-216.

[19] Løhre, C., Kleinert, M., Barth, T., 2017. Organosolv extraction of softwood combined with lignin-to-liquid solvolysis as a semi continuous percolation reactor. Biomass Bioenergy. 99, 147-155.

[20] Mood, S.H., Golfeshan, A.H., Tabatabaei, M., Jouzani, G.S., Najafi, G.H., Gholami, M., Ardjmand, M., 2013. Lignocellulosic biomass to bioethanol, a comprehensive review with a focus on pretreatment. Renew. Sust. Energy Rev. 27, 77-93.

[21] Nigam, P.S., Singh, A., 2011. Production of liquid biofuels from renewable resources. Prog. Energy Combust. Sci. 37(1), 52-68.

[22] Oregui-Bengoechea, M., Hertzberg, A., Miletić, N., Arias, P.L. Barth, T., 2015. Simultaneous catalytic de-polymerization and hydrodeoxygenation of lignin in water/formic acid media with $\mathrm{Rh} / \mathrm{Al}_{2} \mathrm{O}_{3}, \mathrm{Ru} / \mathrm{Al}_{2} \mathrm{O}_{3}$ and $\mathrm{Pd} / \mathrm{Al}_{2} \mathrm{O}_{3}$ as bifunctional catalysts. J. Anal. Appl. Pyrolysis. 113, 713-722

[23] Oregui-Bengoechea, M., Gandarias, I., Arias, P.L., Barth, T., 2017. Unravelling the role of formic acid and the type of solvent in the catalytic conversion of lignin: a holistic approach. ChemSusChem. 10(4), 754-766

[24] Singh, A., Pant, D., Korres, N.E., Nizami, A.S., Prasad, S., Murphy, J.D., 2010. Key issues in life cycle assessment of ethanol production from lignocellulosic biomass: challenges and perspectives. Bioresour. Technol. 101(13), 5003-5012.

[25] Singh, R., Prakash, A., Dhiman, S.K., Balagurumurthy, B., Arora A.K., Puri, S.K., Bhaskar, T., 2014. Hydrothermal conversion of lignin to substituted phenols and aromatic ethers. Bioresour. Technol. 165, 319-322.

[26] Sluiter, A., Hames, B., Ruiz, R., Scarlata, C., Sluiter, J., Templeton, D., 2008. Determination of ash in biomass, laboratory analytical procedure (LAP), Golden, CO, USA. NREL/TP-510-42622.

[27] Tanaka, K., Berntsen, T., Fuglestvedt, J.S, Rypdal, K., 2012. Climate effects of emission standards: the case for gasoline and diesel cars. Environ. Sci. Technol. 46(9), 5205-5213.

[28] Zhang, X., Tu, M., Paice, M.G., 2011. Routes to potentia bioproducts from lignocellulosic biomass lignin and hemicelluloses. BioEnergy Res. 4(4), 246-257 


\section{Supplementary Material}

Table S1.

Extended overview of the product output of the LtL-process experiments together with pressure and torque at the end of each experiment (for experimental conditions, see Table 1).

\begin{tabular}{lccccc}
\hline Experiment & $\begin{array}{c}\text { Pressure } \\
(\mathbf{b a r})\end{array}$ & $\begin{array}{c}\text { Torque } \\
(\mathbf{N m})\end{array}$ & $\begin{array}{c}\text { Oil yield } \\
(\boldsymbol{\%})^{*}\end{array}$ & $\begin{array}{c}\text { Char yield } \\
(\boldsymbol{\%})^{*}\end{array}$ & $\begin{array}{c}\text { Lignin mass } \\
\text { balance (\%)* }\end{array}$ \\
\hline L.W.S-320 & 195 & 0.534 & 43.43 & 17.36 & 60.78 \\
L.W.NS-320 & 215 & 0 & 24.85 & 31.30 & 56.15 \\
H.W.S-320 & 265 & 0.514 & 55.03 & 9.43 & 64.46 \\
H.W.NS-320 & 292 & 0 & 32.11 & 17.50 & 49.61 \\
L.W.S-350 & 251 & 0.509 & 42.02 & 18.42 & 60.44 \\
L.W.NS-350 & 237 & 0 & 17.56 & 29.11 & 46.67 \\
H.W.S-350 & 336 & 0.510 & 45.53 & 10.74 & 56.27 \\
H.W.NS-350 & 323 & 0 & 33.80 & 19.27 & 53.07 \\
L.Et.S-320 & 165 & 0.514 & 52.06 & 11.46 & 63.52 \\
L.Et.NS-320 & 169 & 0 & 38.17 & 35.64 & 73.81 \\
M.Et.S-320 & 269 & 0.519 & 72.17 & 8.81 & 80.98 \\
M.Et.NS-320 & 279 & 0 & 39.61 & 29.56 & 69.18 \\
L.Et.S-350 & 139 & 0.514 & 50.13 & 28.64 & 78.77 \\
L.Et.NS-350 & 190 & 0 & 32.25 & 35.11 & 67.36 \\
M.Et.S-350 & 310 & 0.552 & 57.38 & 13.37 & 70.75 \\
M.Et.NS-350 & 341 & 0 & 31.34 & 29.92 & 61.26 \\
\hline
\end{tabular}

* All yields are calculated on ash-free basis.

Table S2.

Elemental composition as well as the $\mathrm{H} / \mathrm{C}$ and $\mathrm{O} / \mathrm{C}$ ratios of all the LtL-oils and chars.

\begin{tabular}{|c|c|c|c|c|c|c|c|c|c|c|c|c|}
\hline \multirow{3}{*}{ Experiment } & \multicolumn{6}{|c|}{ Oil } & \multicolumn{6}{|c|}{ Char } \\
\hline & $\mathbf{C}$ & $\mathbf{H}$ & $\mathbf{N}$ & $\mathbf{O}$ & \multirow{2}{*}{$\mathrm{H} / \mathrm{C}$} & \multirow{2}{*}{$\mathrm{O} / \mathrm{C}$} & $\mathbf{C}$ & $\mathbf{H}$ & $\mathbf{N}$ & $\mathbf{O}$ & \multirow{2}{*}{$\mathbf{H} / \mathbf{C}$} & \multirow{2}{*}{$\mathrm{O} / \mathrm{C}$} \\
\hline & \multicolumn{4}{|c|}{ Moles (\%) } & & & \multicolumn{4}{|c|}{ Moles (\%) } & & \\
\hline L.W.S-320 & 6.19 & 7.17 & 0.084 & 1.08 & 1.16 & 0.174 & 4.81 & 4.77 & 0.049 & 0.99 & 0.99 & 0.205 \\
\hline L.W.NS-320 & 6.56 & 7.14 & 0.076 & 0.81 & 1.09 & 0.124 & 5.51 & 4.20 & 0.051 & 1.00 & 0.76 & 0.182 \\
\hline H.W.S-320 & 6.28 & 7.50 & 0.057 & 1.01 & 1.19 & 0.161 & 4.11 & 3.75 & 0.047 & 0.84 & 0.91 & 0.204 \\
\hline H.W.NS-320 & 6.52 & 7.53 & 0.065 & 0.82 & 1.15 & 0.126 & 5.42 & 3.91 & 0.046 & 0.60 & 0.72 & 0.111 \\
\hline L.W.S-350 & 6.22 & 8.12 & 0.056 & 1.02 & 1.31 & 0.165 & 5.58 & 4.73 & 0.045 & 0.48 & 0.85 & 0.085 \\
\hline L.W.NS-350 & 6.55 & 8.05 & 0.049 & 0.78 & 1.23 & 0.120 & 5.73 & 4.45 & 0.047 & 0.78 & 0.78 & 0.136 \\
\hline H.W.S-350 & 6.19 & 7.87 & 0.071 & 1.05 & 1.27 & 0.169 & 4.31 & 3.87 & 0.042 & 0.86 & 0.90 & 0.200 \\
\hline H.W.NS-350 & 6.53 & 7.64 & 0.064 & 0.81 & 1.17 & 0.125 & 5.27 & 3.85 & 0.045 & 0.81 & 0.73 & 0.154 \\
\hline L.Et.S-320 & 6.13 & 7.87 & 0.083 & 1.08 & 1.28 & 0.176 & 5.08 & 4.69 & 0.046 & 0.32 & 0.92 & 0.062 \\
\hline L.Et.NS-320 & 5.96 & 8.02 & 0.092 & 1.19 & 1.35 & 0.200 & 6.09 & 4.34 & 0.054 & 0.65 & 0.71 & 0.106 \\
\hline M.Et.S-320 & 5.94 & 8.20 & 0.080 & 1.21 & 1.38 & 0.203 & 4.16 & 3.76 & 0.035 & 0.72 & 0.90 & 0.173 \\
\hline M.Et.NS-320 & 5.72 & 8.25 & 0.091 & 1.35 & 1.44 & 0.237 & 6.07 & 4.91 & 0.052 & 0.50 & 0.81 & 0.082 \\
\hline L.Et.S-350 & 6.15 & 8.36 & 0.036 & 1.08 & 1.36 & 0.176 & 5.99 & 4.70 & 0.050 & 0.55 & 0.78 & 0.092 \\
\hline L.Et.NS-350 & 6.06 & 8.30 & 0.097 & 1.09 & 1.37 & 0.181 & 6.23 & 4.01 & 0.054 & 0.56 & 0.64 & 0.089 \\
\hline M.Et.S-350 & 6.24 & 8.07 & 0.080 & 0.99 & 1.29 & 0.158 & 5.027 & 3.890 & 0.041 & 0.60 & 0.77 & 0.119 \\
\hline M.Et.NS-350 & 6.05 & 8.26 & 0.090 & 1.11 & 1.37 & 0.183 & 6.075 & 4.112 & 0.050 & 0.56 & 0.68 & 0.091 \\
\hline
\end{tabular}

